\title{
Cost effectiveness analysis of azithromycin and doxycycline for Chlamydia trachomatis infection in women: A Canadian perspective
}

Fawziah Marra BSc(Pharm) PharmD, Carlo A Marra BSc(Pharm) PharmD, David M Patrick MD MHSc FRCPC

F MARRA, CA MARRA, DM PATRICK. Cost effectiveness analysis of azithromycin and doxycycline for Chlamydia trachomatis infection in women: A Canadian perspective. Can J Infect Dis 1997;8(4):202-208.

OBJECTIVE: To assess the cost effectiveness of azithromycin versus doxycycline therapy for cervical Chlamydia trachomatis infections in Canada.

DESIGN: A predictive decision analytic model using previously published clinical and economic evaluations, expert opinion and costs of medical care in Canada.

POPULATION: A hypothetical cohort of 5000 women followed over 10 years.

INTERVENTIONS: Two diagnostic strategies were compared, laboratory confirmed diagnosis (LCD) and presumptive diagnosis (PD) of $C$ trachomatis infection. Under each strategy, two treatment alternatives were analyzed, a single $1 \mathrm{~g}$ dose of azithromycin and a seven-day course of doxycycline as $100 \mathrm{mg}$ twice daily.

RESULTS: Despite a fourfold higher acquisition cost, under base case conditions, for both diagnostic strategies, the azithromycin treatment alternative was more cost effective than the doxycycline alternative. For the LCD model, the cost per cure for patients receiving azithromycin was $\$ 184.76$ compared with $\$ 240.59$ for patients receiving doxycycline, resulting in an incremental cost of $\$ 55.83$. For the PD model, the cost per cure for patients treated with azithromycin was $\$ 51.48$ compared with $\$ 51.82$, resulting in an incremental cost of $\$ 0.34$. For the hypothetical cohort of 5000 women, the use of azithromycin translates into a projected annual cost savings of $\$ 279,150$ and $\$ 1,700$ for the LCD and PD models, respectively. In one-way sensitivity analyses for the LCD model, no clinically plausible changes in the base case estimates changed the results of the cost effectiveness outcome. In the PD model, clinically plausible changes in the probabilities of doxycycline cure, pelvic inflammatory disease, sequelae and chlamydia infection were found to alter the cost effectiveness outcome.

CONCLUSIONS: Based on the results from our model, the azithromycin strategy should be employed for the treatment of laboratory confirmed cases. However, for presumptive cases, azithromycin should be used only if the probabilities of C trachomatis and pelvic inflammatory disease are more than 19\%, doxycycline effectiveness is less than $78 \%$, or the cost of azithromycin is less than $\$ 19.00$.

Key Words: Azithromycin, Chlamydia trachomatis, Doxycycline, Pharmacoeconomics

Presented in part at the 36 th Interscience Conference on Antimicrobial Agents and Chemotherapy, New Orleans, Louisiana, September 15-18, 1996

Department of Pharmacy, Vancouver Hospital and Health Sciences Centre; Faculty of Pharmaceutical Sciences and Division of Infectious Diseases, Faculty of Medicine, University of British Columbia; Pharmaceutical Outcomes Research Program, British Columbia's Children's and Women's Hospitals, Vancouver, British Columbia

Correspondence and reprints: Dr F Marra, Department of Pharmacy, Vancouver Hosptial and Health Sciences Centre, 855 West 12 th Avenue, Vancouver, British Columbia V5Z 1M9. Telephone 604-875-4077, fax 604-875-5267, e-mail fawziah@unixg.ubc.ca

Received for publication May 28, 1996. Accepted December 11, 1996 


\title{
Analyse coût-efficacité de l'azithromycine et de la doxycycline dans l'infection à Chlamydia trachomatis chez la femme au Canada
}

\begin{abstract}
OBJECTIF : Évaluer le rapport coût-efficacité de l'azithromycine versus la doxycycline dans les infections cervicales à Chlamydia trachomatis au Canada.

MODÈLE : Modèle prédictif d'analyse décisionnelle basée sur des évaluations cliniques et économiques déjà publiées, sur l'opinion d'experts et sur les coûts des soins de santé au Canada.

POPULATION : Cohorte hypothétique de 5000 femmes suivies sur une période de dix ans.

INTERVENTIONS : Deux stratégies diagnostiques ont été comparées : le diagnostic confirmé en laboratoire (DCL) et le diagnostic présomptif (DP) de l'infection à $C$. trachomatis. Selon chaque stratégie, deux choix de traitement ont été analysés : une dose simple de $1 \mathrm{~g}$ d'azithromycine et un traitement de sept jours à la doxycycline à raison de $100 \mathrm{mg}$ deux fois par jour.

RÉSULTATS : Malgré des coûts d'acquisition quatre fois plus grands, selon les scénarios de référence, pour les deux stratégies diagnostiques, le traitement à l'azithromycine s'est révélé plus économique que la doxycycline. Pour le modèle DCL, le coût par traitement pour les patientes sous azithromycine a été de 184,76 \$, contre 240,59 \$ pour les patientes sous doxycycline, donnant lieu à une différence de 55,83\$. Pour le modèle DP, le coût par traitement pour les patientes sous azithromycine a été de $51,48 \$$, contre $51,82 \$$, pour une différence de $0,34 \$$. Pour la cohorte hypothétique de 5000 femmes, l'emploi de l'azithromycine se traduit par des économies annuelles potentielles de $279150 \$$ et de $1700 \$$ pour les modèles DCL et DP respectivement. Lors d'analyses de sensibilité univariées pour le modèle DCL, aucun changement clinique plausible des estimations des scénarios de référence n’a modifié les résultats de l'analyse coût-efficacité. Dans le modèle DP, les changements cliniques plausibles des probabilités de guérison de la pelvipéritonite par la doxycycline, des séquelles et des infections à Chlamydia ont influé sur les résultats de l'analyse coût-efficacité.

CONCLUSIONS : Sur la base des résultats de notre modèle, le traitement à l'azithromycine devrait être employé dans le traitement des cas confirmés en laboratoire. Toutefois, pour les cas présomptifs, l'azithromycine ne doit être utilisée que si les probabilités d'infection à C. trachomatis et de pelvipéritonite sont plus grandes que $19 \%$, si l'efficacité de la doxycycline est inférieure à $78 \%$ ou si le coût de l'azithromycine est inférieur à 19,00\$.
\end{abstract}

$\mathrm{G}$ enital tract infection caused by Chlamydia trachomatis remains the most frequently reported bacterial sexually transmitted disease in Canada. Despite limited screening of males, nearly 50,000 reports were made in 1993 (1). Young sexually active women are the most commonly afflicted, with 1200 per 100,000 of the population being infected (2). Chlamydial infection may be complicated by pelvic inflammatory disease (PID), epididymitis, perihepatitis and Reiter's syndrome in adults, as well as pneumonia and ophthalmia in the newborn $(3,4)$. Such conditions contribute to both patient suffering and direct health care costs (5).

Effective therapy of uncomplicated $C$ trachomatis infection is key to preventing complications and reducing the spread of the pathogen (6). Several trials have demonstrated equivalent efficacy of single dose azithromycin and one week of therapy with doxycycline, both for proven chlamydial infection and for syndromes for which $C$ trachomatis is frequently the causative pathogen (7-12). Although single dose azithromycin is currently marketed at greater cost than a course of doxycycline, it may be cost effective under a variety of assumptions within the United States health care system (13). This study used decision analysis to determine whether azithromycin therapy might also be cost effective in the Canadian health care system where the cost of managing complications remains considerably lower than in the United States.

\section{METHODS}

Analysis type: Decision tree models were used to assess the cost effectiveness of two pharmacotherapeutic interventions for the treatment of $C$ trachomatis cervicitis from the perspective of the Canadian health care system. The two treatment alternatives analyzed were oral azithromycin $1 \mathrm{~g}$ as a single dose, and oral doxycycline $100 \mathrm{mg}$ twice daily for seven days.
Each of the treatment alternatives was evaluated under the following two diagnostic scenarios: laboratory confirmed (ie, culture positive) $C$ trachomatis infection before antibiotic therapy, and presumptive diagnosis based on clinical signs and symptoms of the patient or partner. These included mucopurulent cervicitis, epididymitis and urethritis (gonococcal or nongonococcal) in male partners, or a laboratory confirmed diagnosis of Neisseria gonorrhoeae.

Decision analysis model: The models used in this evaluation were derived from Haddix et al (13) and adapted to the Canadian health care system. For each of the diagnostic strategies, a decision tree was constructed (Figures 1,2) using Data (Version 3.0, TreeAge Software Inc, Massachusetts). Probabilities and costs incorporated into each decision tree were based on published findings, hospital patient costing departments and expert opinion.

For the laboratory confirmed treatment strategy, there were eight outcomes for each therapeutic intervention, while for the presumptive strategy there were 10 possible outcomes. In both strategies, because screening of $C$ trachomatis infection occurs in the majority of pregnant women and both doxycycline and azithromycin are contraindicated for the treatment of $C$ trachomatis in pregnancy, none of the sequelae associated with neonates (conjunctivitis and pneumonia) was included in either model. In clinical trials the incidence and severity of adverse drug reactions were mild and not significantly different in both doxycycline- and azithromycin-treated individuals, and thus the costs associated with the treatment of adverse drug reactions were not included in this analysis (7-12).

Probability estimates: To obtain the probability estimates a MEDLINE search of studies published in English from January 1966 to December 1995 was conducted. Reports involving effi- 


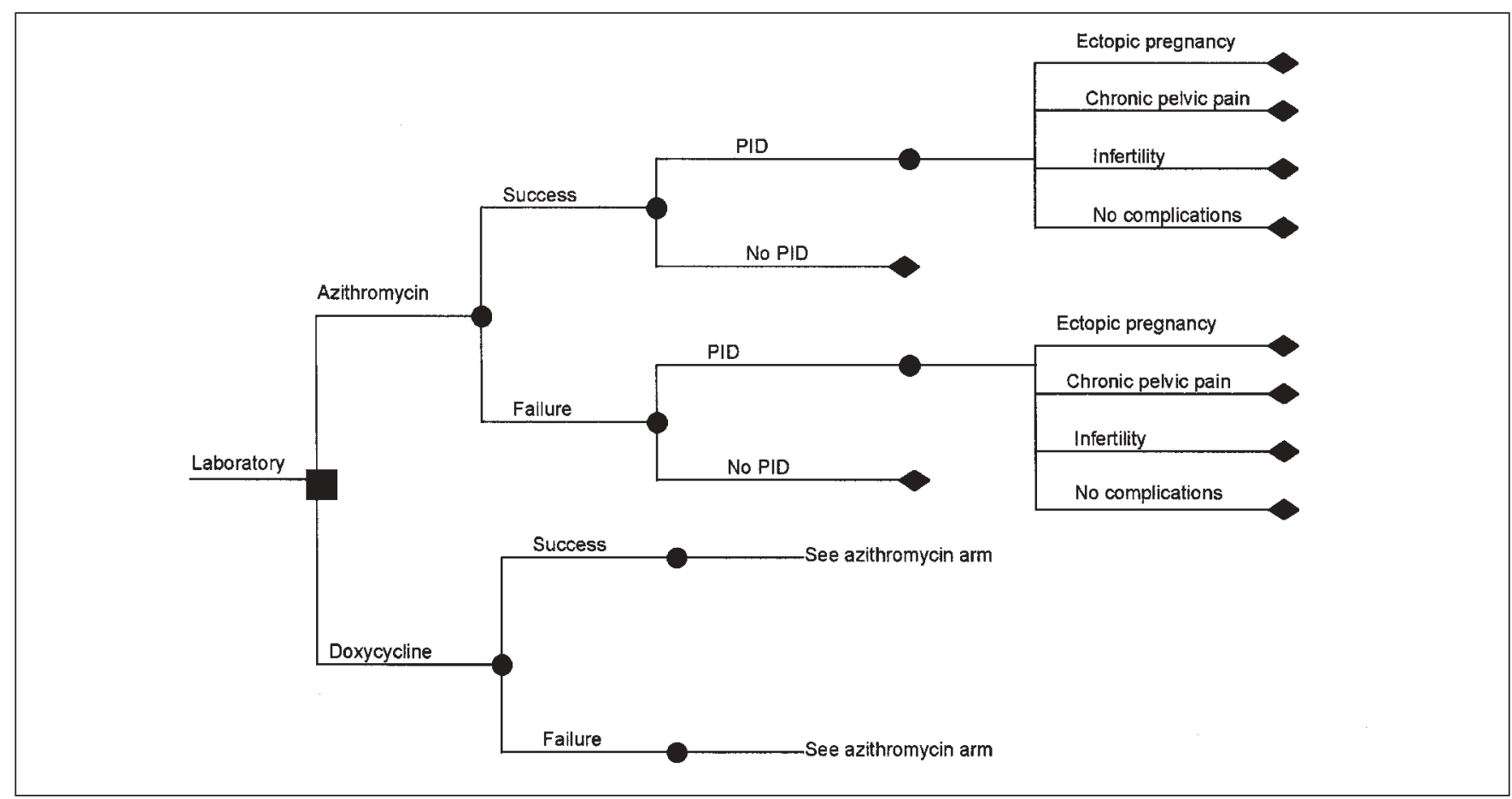

Figure 1) Decision tree showing outcomes for the treatment of Chlamydia trachomatis in women with a laboratory confirmed diagnosis. Decision node; Chance nodes; $\checkmark$ End of a branch; PID Pelvic inflammatory disease

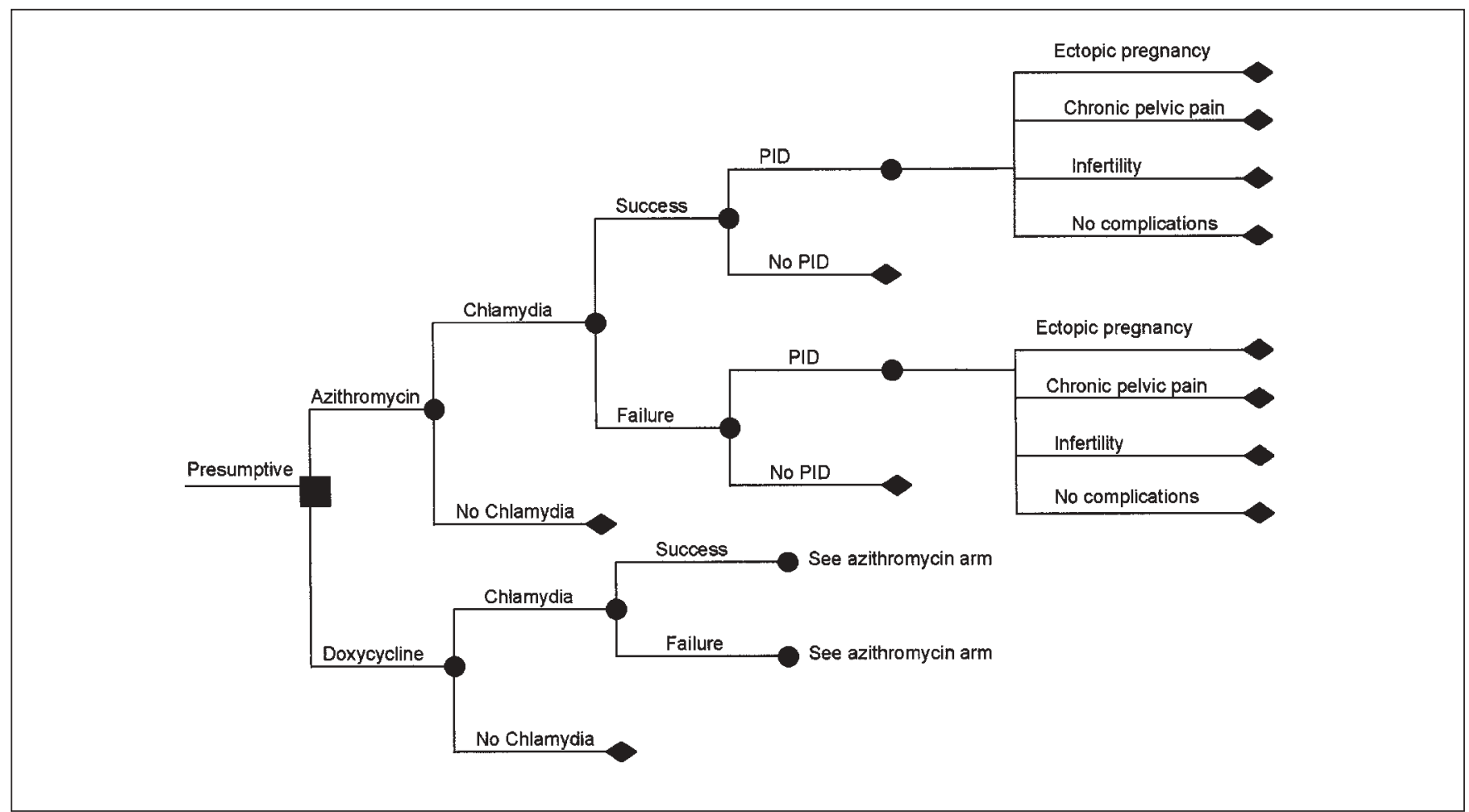

Figure 2) Decision tree showing outcomes for the treatment of Chlamydia trachomatis in women with a presumptive diagnosis. $\square$ Decision node; Chance nodes; End of a branch; PID Pelvic inflammatory disease

cacy and toxicity evaluation of azithromycin and doxycycline for $C$ trachomatis, probability and estimates of PID, ectopic pregnancy, chronic pelvic pain and infertility were sought. Key words employed included 'C trachomatis', 'azithromycin', 'doxycycline', 'PID', 'ectopic pregnancy', 'chronic pelvic pain', 'infertility', 'cost effectiveness' and 'pharmacoeconomics'. To augment this search, a manual search of the literature was conducted to locate additional reports which were not identified in the computer-assisted review. In addition to the information obtained from the literature review, probability esti- 
TABLE 1

Probabilities used in the analysis

\begin{tabular}{lccc}
\hline & $\begin{array}{c}\text { Probability estimate } \\
\text { Base }\end{array}$ & \\
Variable & $\begin{array}{c}\text { Rase } \\
\text { Efficacy }\end{array}$ & Range & References \\
Azithromycin & 0.965 & $0.93-0.99$ & $7,10-12$ \\
Doxycycline & 0.965 & $0.90-0.95$ & \\
Compliance & & & $13,14-17$ \\
Azithromycin & 1.00 & 1.00 & \\
Doxycycline & 0.80 & $0.50-0.80$ & \\
Pelvic inflammatory & & & $1-822,28-31$ \\
disease & & & \\
After success & 0.06 & $0.06-0.56$ & \\
After failure & 0.20 & $0.12-0.20$ & \\
In-patient treatment & 0.14 & $0.08-0.20$ & \\
Out-patient & 0.86 & $0.80-0.92$ & \\
$\quad$ treatment & & & $1,21,23,24$ \\
Sequelae & & & \\
Chronic pelvic pain & 0.18 & $0.07-0.17$ & \\
Ectopic pregnancy & 0.06 & $0.07-0.10$ & \\
Infertility & 0.20 & $0.07-0.60$ & \\
Treatment rate for & 0.25 & - & \\
$\quad$ infertility & & & \\
Chlamydial infection & 0.20 & $0.10-0.50$ & $1,13,21,24,29$ \\
\hline
\end{tabular}

mates were also obtained from six physicians who are considered experts in managing chlamydial infection and its sequelae (physicians practising in the areas of sexually transmitted diseases, infectious diseases, obstetrics and gynecology).

Table 1 shows the probability estimates used in the model. The efficacy rate of both azithromycin and doxycycline was assumed to be $96.5 \%$, which was an average of the efficacy of the two treatment arms in women in the largest multicentre clinical trial conducted by Martin et al (7). Compliance with azithromycin was assumed to be $100 \%$ because the drug can be administered under supervision in the clinic. Authors of published reports have concluded that compliance with a seven-day doxycycline regimen ranges from $50 \%$ to $80 \%$ (1417). Therefore, to be conservative, in this analysis doxycycline compliance was assumed to be $80 \%$. For the base case analysis, noncompliance with doxycycline was believed to result in treatment failure. Probabilities for PID and sequelae were derived from published clinical trials (18-27) and economic evaluations $(4,13,28)$. The probability of chlamydial infection in the presumptive model was derived from the literature as well as from expert opinion $(1,13,21,24,29)$.

Cost estimates: The analysis was carried out from the perspective of a third-party payer (the Canadian health care system). Only direct medical costs were considered in this analysis. No attempt was made to assess the costs incurred to the provincial government in terms of lost tax revenue from missed work days and lost productivity. In addition, medical costs associated with the first clinic visit and diagnosis of
TABLE 2

Costs used in the base case analysis

\begin{tabular}{lr}
\hline Variable & Cost $(\$)$ \\
\hline Azithromycin 1 g single dose & 18.16 \\
Doxycycline 100 mg BID for & 4.63 \\
$\quad$ seven days & \\
Pelvic inflammatory disease & $1,230.93$ \\
$\quad$ per episode)* $^{*}$ & \\
Chronic pelvic pain $^{\dagger}$ & $5,078.69$ \\
Ectopic pregnancy $^{\ddagger}$ & $4,094.18$ \\
Infertility $^{\S}$ & 881.60 \\
\hline
\end{tabular}

*Weighted average of out-patient (86\%) and in-patient (14\%) treatments; ${ }^{\dagger}$ Discounted at $5 \%$ for two years; ${ }^{\neq}$Discounted at $5 \%$ for five years; ${ }^{\S}$ Discounted at $5 \%$ for 10 years and assumes $25 \%$ of women seek treatment.

C trachomatis infection were assumed to be the same in each of the treatment arms and thus were not factored into the analysis.

The costs used in the decision models are outlined in Table 2 . These costs include hospitalization, physician fees, diagnostic tests, surgery and drug costs associated with the treatment of $C$ trachomatis cervicitis, PID and its sequelae. Because PID is treated on both an in-patient and an out-patient basis $(20,28,30,31)$, a weighted average cost was used for the analysis. Costs of sequelae that would appear in future years (chronic pelvic pain, ectopic pregnancy and infertility) were discounted at an annual rate of $5 \%$ to their present values.

Hospitalization cost was obtained by averaging the results of a survey of several British Columbia hospitals' patient costing departments. Costs associated with physicians' fees for visits, diagnostic tests and surgery were obtained from the British Columbia Medical Association Guide to Fees (32). Drug costs were obtained from the British Columbia Sexually Transmitted Disease Pharmacy. This Ministry of Health funded pharmacy provides antibiotics to primary care practitioners across the province without charging a professional fee.

Sensitivity and break-even analyses: One-way sensitivity analyses were conducted for each variable for which the values were based on estimates or were uncertain. Values used for the range of the sensitivity analyses were confidence intervals (when available) or values deemed plausible in the clinical realm. These variables include doxycycline effectiveness, probabilities and cost of treatment for PID and sequelae, and prevalence of chlamydial infection in women who are presumptively treated. Break-even analyses were also performed on these variables to calculate the point at which both azithromycin and doxycycline are cost-equivalent.

\section{RESULTS}

Cost per treatment analysis: A single $1 \mathrm{~g}$ dose of azithromycin is four times more expensive than a seven-day course of twice daily doxycycline. For example, the costs of azithromycin and doxycycline for the treatment of a hypothetical cohort of 5000 women are $\$ 90,800$ and $\$ 23,150$, respectively. Despite this large difference in drug costs, this analysis indicates that azithromycin is the more cost effective treatment strategy.

Using base case assumptions, there is a lower cost per cure 
TABLE 3

Costs and savings per case cured

\begin{tabular}{lccc}
\hline Variable & Azithromycin & $\begin{array}{c}\text { Cost } \mathbf{( \$ )} \\
\text { Doxycycline }\end{array}$ & Difference \\
\hline $\begin{array}{c}\text { Laboratory } \\
\text { confirmed }\end{array}$ & 184.76 & 240.59 & 55.83 \\
$\begin{array}{c}\text { Presumptively } \\
\text { treated }\end{array}$ & 51.48 & 51.82 & 0.34 \\
\hline
\end{tabular}

TABLE 4

Costs and savings in a cohort of 5000 women

\section{Cost (\$)}

\begin{tabular}{lccc} 
Variable & Azithromycin & Doxycycline & Difference \\
\hline $\begin{array}{l}\text { Laboratory } \\
\text { confirmed }\end{array}$ & 923,800 & $1,202,950$ & 279,150 \\
$\begin{array}{l}\text { Presumptively } \\
\text { treated }\end{array}$ & 257,400 & 259,100 & 1,700 \\
\hline
\end{tabular}

TABLE 5

Sensitivity and break-even analyses in the laboratory confirmed model

\begin{tabular}{lcc}
\hline Variable & $\begin{array}{c}\text { Choose } \\
\text { azithromycin }\end{array}$ & $\begin{array}{c}\text { Choose } \\
\text { doxycycline }\end{array}$ \\
\hline $\begin{array}{l}\text { Probability of doxycycline } \\
\text { cure }\end{array}$ & $<93 \%$ & $>93 \%$ \\
$\begin{array}{l}\text { Probability of PID } \\
\text { Probability of chronic pelvic } \\
\text { pain }\end{array}$ & Always & Never \\
$\begin{array}{l}\text { Probability of ectopic } \\
\text { pregnancy }\end{array}$ & Always & Never \\
$\begin{array}{l}\text { Probability of infertility } \\
\text { Cost of PID }\end{array}$ & Always & Never \\
$\begin{array}{l}\text { Cost of chronic pelvic pain } \\
\text { Cost of ectopic pregnancy }\end{array}$ & Always & Never \\
Cost of infertility & Always & Never \\
Cost of azithromycin & Always & Never \\
\hline
\end{tabular}

PID Pelvic inflammatory disease

for individuals treated with azithromycin than doxycycline in the laboratory confirmed and presumptive treatment models (Tables 3,4). For the laboratory confirmed model, the cost per cure for patients receiving azithromycin is $\$ 184.76$ compared with $\$ 240.59$ for patients receiving doxycycline. This results in an incremental cost of $\$ 55.83$. For the presumed treatment model, the cost per cure for patients treated with azithromycin is $\$ 51.48$ compared with $\$ 51.82$, resulting in an incremental cost of $\$ 0.34$.

The use of azithromycin in a cohort of 5000 British Columbia women with a laboratory confirmed diagnosis of $C$ trachomatis results in a cost savings of $\$ 279,150$ to the British Columbia health care system. Under base case conditions, azithromycin is more cost effective to use in women with a

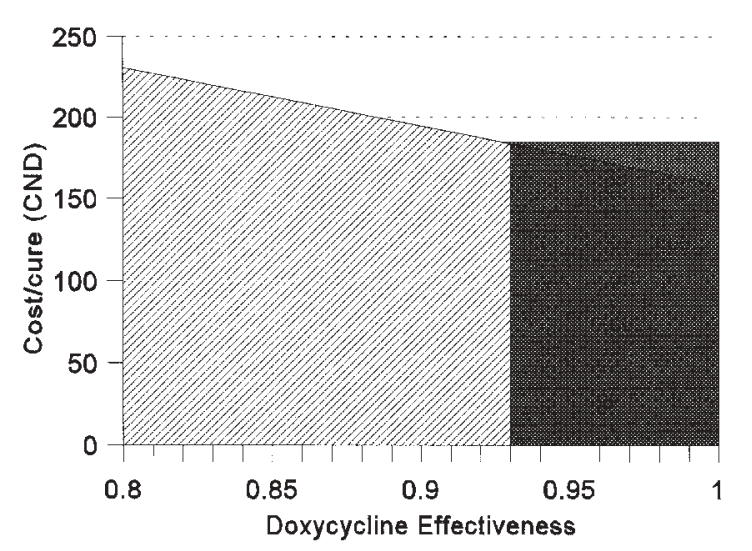

Azithrom ycin dominant
Doxycycline dom inant

Figure 3) Effect of doxycycline effectiveness on the cost per case cured in the laboratory confirmed model. The x axis shows the effectiveness of doxycycline; the $y$ axis shows the cost per cure, which decreases as doxycycline effectiveness increases. At rates of doxycycline effectiveness less than 0.93, the azithromycin strategy is the dominant one because it results in lower cost per cure than doxycycline. At rates of doxycycline effectiveness more than 0.93, the doxycycline strategy is the dominant one

presumptive diagnosis of $C$ trachomatis. However, the incremental cost difference is only $\$ 1,700$ for a cohort of 5000 British Columbia women.

Univariate sensitivity and break-even analyses: Sensitivity and break-even analyses were performed around doxycycline effectiveness, probabilities of PID and sequelae, cost of treatment for PID and sequelae, and prevalence of chlamydial infection in women who are presumptively treated.

In the laboratory confirmed model, no clinically plausible changes in the baseline estimates of the cost of treating PID, the probability of sequelae and the cost of treating sequelae influenced the results of the cost-effectiveness outcome (Table 5). For doxycycline to be the more cost effective alternative, the probability of PID that results from treatment failure would have to be less than $9 \%$. In addition, the effectiveness of doxycycline would have to be $93 \%$ for doxycycline to be more cost effective than azithromycin (Figure 3). For this effectiveness rate to occur, $65 \%$ of noncompliant patients would have to achieve clinical cure. Authors of a study addressing this issue found that the true incidence of clinical cure in noncompliant patients receiving doxycycline was only $30 \%$ (15). For the laboratory confirmed model, azithromycin remains the dominant treatment strategy as long as the cost of a $1 \mathrm{~g}$ dose of azithromycin remains below $\$ 74.00$.

In the presumptive treatment model, many clinically plausible changes in the baseline estimates influenced the results of the study (Table 6). For example, the values for the probability of doxycycline cure, the probability of PID, the probability of sequelae and the probability of chlamydial infection were found to change the nature of the cost effectiveness outcome that might be achieved in the clinical setting. 


\section{DISCUSSION}

From the perspective of the British Columbia Health Care System, our decision analysis suggests that under basecase assumptions, azithromycin is a more cost effective treatment than doxycycline for both diagnostic strategies. When these results are extrapolated to a cohort of women approximately the same size as the number of women treated each year in British Columbia, the use of azithromycin would result in considerable cost savings despite its fourfold higher acquisition cost. For example, in British Columbia, almost 5000 women are treated annually for $C$ trachomatis cervicitis. Approximately $95 \%$ of these women have a laboratory confirmed diagnosis while the remaining $5 \%$ are treated based upon a presumptive diagnosis. Based on this breakdown, the actual cost savings that could be realized in British Columbia by using azithromycin is estimated to be $\$ 279,150$. Calculated at a national level, this cost savings represents approximately $\$ 3$ million in avoided medical costs.

In general, our model is conservative with respect to the cost effectiveness of the azithromycin treatment. For example, we have only considered the direct medical costs of treating chlamydia infections and their sequelae. Indirect costs to the provincial government may include decreased tax revenue due to work losses and a reduction in productivity. If the perspective is expanded to that of society, indirect and intangible costs, such as a reduction in quality of life, pain and suffering, need to be considered. We have considered the highest reported value for compliance with the doxycycline regimen $(80 \%)$, thus maximizing its effectiveness. In addition, we did not consider the costs of treating the secondary transmission of chlamydia infections to sexual partners or neonates. Because the azithromycin strategy has a higher effectiveness rate, these findings further increase the value of the cost effectiveness ratio. With respect to adverse drug reactions, we have assumed that the frequency, magnitude and cost of their treatment would be equivalent in both treatment strategies despite the longer duration of doxycycline treatment.

Although this study discusses the issue from a Canadian perspective, investigators from the United States and Sweden have arrived at similar conclusions. Authors of two well designed studies from the United States have concluded that azithromycin is the more cost effective treatment strategy in the American health care system $(13,33)$. However, authors of another study comparing five treatment strategies for $C$ trachomatis cervicitis concluded that doxycycline was the most cost-effective strategy (34). These authors had assumed equivalent effectiveness between the two agents and found that azithromycin became a more cost effective strategy when the initial cure rate of azithromycin exceeded that of doxycycline by three percentage points. Unfortunately, the likelihood of equivalent effectiveness between azithromycin and doxycycline is remote when one considers that the compliance rate for a seven-day doxycycline regimen has been reported to be between $50 \%$ and $80 \%(13,14-17)$.

In the Swedish study conducted by Genç and Mårdh (35), the objective was to assess the cost effectiveness of identifying and treating asymptomatic female carriers of $C$ trachoma-
TABLE 6

Sensitivity and break-even analyses in the presumptive treatment model

\begin{tabular}{lcc}
\hline Variable & $\begin{array}{c}\text { Choose } \\
\text { azithromycin }\end{array}$ & $\begin{array}{c}\text { Choose } \\
\text { doxycycline }\end{array}$ \\
\hline Probability of doxycycline cure & $<78 \%$ & $>78 \%$ \\
Probability of PID & $>19 \%$ & $<19 \%$ \\
Probability of chronic pelvic & $>17 \%$ & $<17 \%$ \\
$\quad$ pain & $>4 \%$ & $<4 \%$ \\
Probability of ectopic & & \\
$\quad$ pregnancy & $>13 \%$ & $<13 \%$ \\
Probability of infertility & $>19 \%$ & $<19 \%$ \\
Probability of Chlamydia & & \\
trachomatis & $>\$ 1,170$ & $<\$ 1,170$ \\
Cost of PID & $>\$ 4,730$ & $<\$ 4,730$ \\
Cost of chronic pelvic pain & $>\$ 3,040$ & $<\$ 3,040$ \\
Cost of ectopic pregnancy & $>\$ 570$ & $<\$ 570$ \\
Cost of infertility & $<\$ 19$ & $>\$ 19$ \\
Cost of azithromycin & & \\
\hline PID Pelvic infamatory disease & & \\
\hline
\end{tabular}

PID Pelvic inflammatory disease

tis. The identification strategies evaluated were tissue cell culture, confirmed immunoassay, DNA amplification assays based on either polymerase chain reaction or ligase chain reactions, or no screening. In addition, the treatment strategies of a single $1 \mathrm{~g}$ dose of azithromycin, a seven-day course of doxycycline $100 \mathrm{mg}$ orally twice a day, or no treatment were compared. The authors found that for asymptomatic carriers of $C$ trachomatis, screening with a DNA amplification assay combined with the single $1 \mathrm{~g}$ dose of azithromycin was the most cost effective strategy when the prevalence of infection was equal to or greater than $6 \%$.

\section{CONCLUSIONS}

Based on the results from our model, the azithromycin strategy should be employed for the treatment of laboratory confirmed cases. However, for presumptive cases, azithromycin should be used only if the probabilities of $C$ trachomatis and PID are greater than 19\%, doxycycline effectiveness is less than $78 \%$, or the cost of azithromycin is less than $\$ 19.00$.

\section{REFERENCES}

1. Health and Welfare Canada. Canadian guidelines for the prevention, diagnosis, management, and treatment of sexually transmitted diseases in neonates, children, adolescents and adults. Ottawa: Health and Welfare Canada, 1995.

2. Sexually transmitted disease control 1994 Annual Report. Victoria: BC Ministry of Health and Ministry Responsible For Seniors, 1995.

3. Bowie W, Holmes K. Chlamydial diseases. In: Mandell G, Douglas $\mathrm{R}$, Bennett J, eds. Principles and Practice of Infectious Diseases. New York: Churchill Livingstone, 1990:1424-31.

4. Washington AE, Johnson RE, Sanders LL. Chlamydia trachomatis infections in the United States: What are they costing us? JAMA 1987;257:2070-2.

5. Bowie WR. Drug therapies for sexually transmitted diseases: clinical and economic considerations. Drugs 1995;49:496-515.

6. Hillis S, Black C, Newhall J, Walsh C, Groseclose SL. New opportunities for chlamydia prevention: Applications of science to public health practice. Sex Transm Dis 1995;22:197-202. 
7. Martin DH, Mroczkowski TF, Dalu ZA, et al. A controlled trial of a single dose of azithromycin for the treatment of chlamydial urethritis and cervicitis. N Engl J Med 1992;327:921-5.

8. Stamm WE, Hicks CB, Martin DH, et al. Azithromycin for empirical treatment of the nongonococcal syndrome in men. JAMA 1995;274:545-9.

9. Steingrimsson O, Olafsson $\mathrm{JH}$, Thorarinsson $\mathrm{H}$, et al. Single dose azithromycin treatment of gonorrhea and infections caused by $C$ trachomatis and $U$ urealyticum in men. Sex Transm Dis 1994;21:43-6.

10. Ossewaarde JM, Plantema FH, Rieffe M, et al. Efficacy of single dose azithromycin versus doxycycline in the treatment of cervical infections caused by Chlamydia trachomatis. Eur J Clin Microbiol 1992;11:693-6.

11. Hammerschlag MR, Golden NH, Oh MK, et al. Single dose of azithromycin for the treatment of genital chlamydial infections in adolescents. J Pediatr 1993;122:961-5.

12. Steingrimsson O, Olafsson JH, Thorarinsson $\mathrm{H}$, et al. Azithromycin in the treatment of sexually transmitted disease. J Antimicrob Agents Chemother 1990;25(Suppl A):109-14.

13. Haddix AC, Hillis SD, Kassler WJ. The cost effectiveness of azithromycin for Chlamydia trachomatis infections in women. Sex Transm Dis 1995;22:274-80.

14. Stamm WE. Problems in the treatment of bacterial sexually transmitted disease. Am J Med 1987;82(Suppl 4A):307-10.

15. Jordan WC. Doxycycline vs tetracycline in the treatment of men with gonorrhea: the compliance factor. Sex Transm Dis 1981;8(Suppl):S105-9.

16. Katz BP, Zwickl BW, Caine VA, et al. Compliance with antibiotic therapy for Chlamydia trachomatis and Neisseria gonorrhoeae. Sex Transm Dis 1992;19:351-9.

17. Brookoff D. Compliance with outpatient antibiotics among women treated in the emergency department for pelvic inflammatory disease. Ann Emerg Med 1992;21:621.

18. Rees E. The treatment of pelvic inflammatory disease. Am J Obstet Gynecol 1980;138:1042-7.

19. Paton DL, Askienazy-Elbhar BD, Henry-Suchet J, et al. Detection of Chlamydia trachomatis in fallopian tissue in women with post-infectious tubal infertility. Am J Obstet Gynecol 1994;171:95-101.

20. Cates W, Joesoef MR, Goldman MB. Atypical pelvic inflammatory disease: Can we identify the clinical predictors? Am J Obstet Gynecol 1993;169:341-6.

21. Centers for Disease Control and Prevention. Recommendations for the prevention and management of Chlamydia trachomatis infections. MMWR 1993;42(RR-12):1-39.

22. Stamm WE, Guinan ME, Johnson C, et al. Effect of treatment regimens for Neisseria gonorrhoeae on simultaneous infection with Chlamydia trachomatis. N Engl J Med 1984;310:545-9.

23. Westrom L. Incidence, prevalence, and trends of acute pelvic inflammatory disease and its consequences in industrialized countries. Am J Obstet Gynecol 1980;138:880-91.

24. Westrom L, Joesoef R, Reynolds G, et al. Pelvic inflammatory disease and fertility: a cohort study of 1,844 women with laparoscopically verified disease and 657 control women with normal laparoscopy. Sex Transm Dis 1992;19:185-92.

25. Westrom L. Effect of acute pelvic inflammatory disease on fertility. Am J Obstet Gynecol 1975;121:707-13.

26. Washington AE, Sweet RL, Shafer MA. Pelvic inflammatory disease and its sequelae in adolescents. J Adolesc Health Care 1985;6:298-310.

27. Svensson L, Mardh PA, Westrom L. Infertility after acute salpingitis with special reference to Chlamydia trachomatis. Fertil Steril 1983;40:322-9.

28. Washington AE, Katz P. Cost of and payment source for pelvic inflammatory disease. Trends and projections, 1983 through 2000. JAMA 1991;266:2565-9.

29. Jones RB, Mammel JB, Shepard M, et al. Recovery of Chlamydia trachomatis from the endometrium of women at risk for chlamydial infection. Am J Obstet Gynecol 1986;155:35-9.

30. Washington AE, Arno PS, Brooks MA. The economic cost of pelvic inflammatory disease. JAMA 1986;255:1735-8.

31. Washington AE, Cates W Jr, Zaidi AA. Hospitalizations for pelvic inflammatory disease. Epidemiology and trends in the United States, 1975 to 1981 . JAMA 1984;251:2529-33.

32. BC Medical Association Guide to Fees. Vancouver: BC Medical Association, 1995.

33. Magid D, Douglas JM Jr, Schwartz S. Doxycycline compared with azithromycin for treating women with genital Chlamydia trachomatis infections: an incremental cost-effectiveness analysis. Ann Intern Med 1996;124:389-99.

34. Nuovo J, Melnikow J, Paliescheskey M, et al. Cost-effectiveness analysis of five different antibiotic regimens for the treatment of uncomplicated Chlamydia trachomatis cervicitis. J Am Board Fam Practice 1995;8:7-16.

35. Genç M, Mårdh PA. A cost-effectiveness analysis of screening and treatment for Chlamydia trachomatis infection in asymptomatic women. Ann Intern Med 1996;124;1-7. 


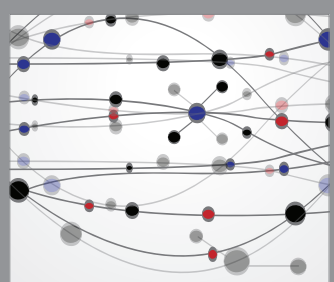

The Scientific World Journal
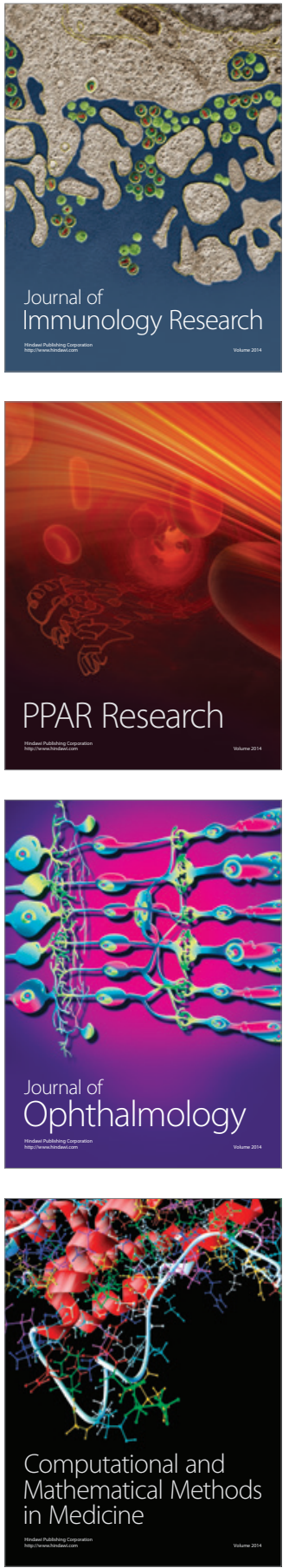

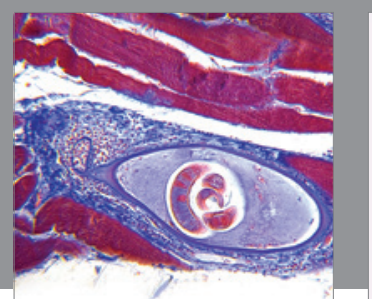

Gastroenterology Research and Practice

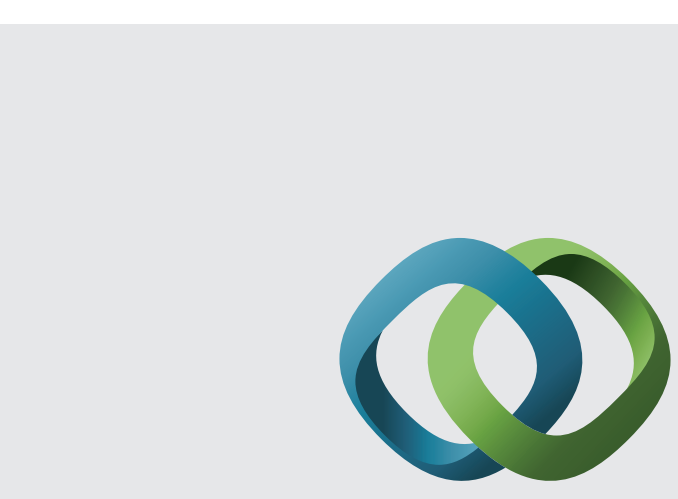

\section{Hindawi}

Submit your manuscripts at

http://www.hindawi.com
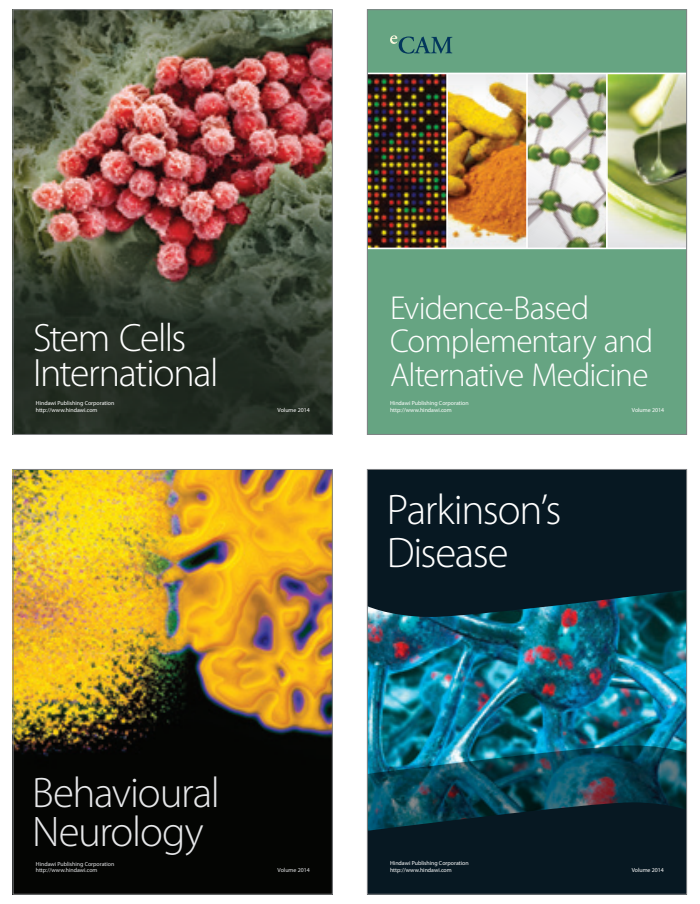
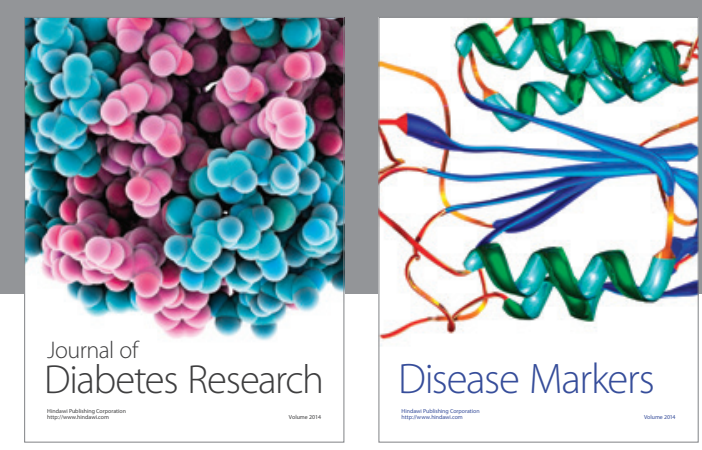

Disease Markers
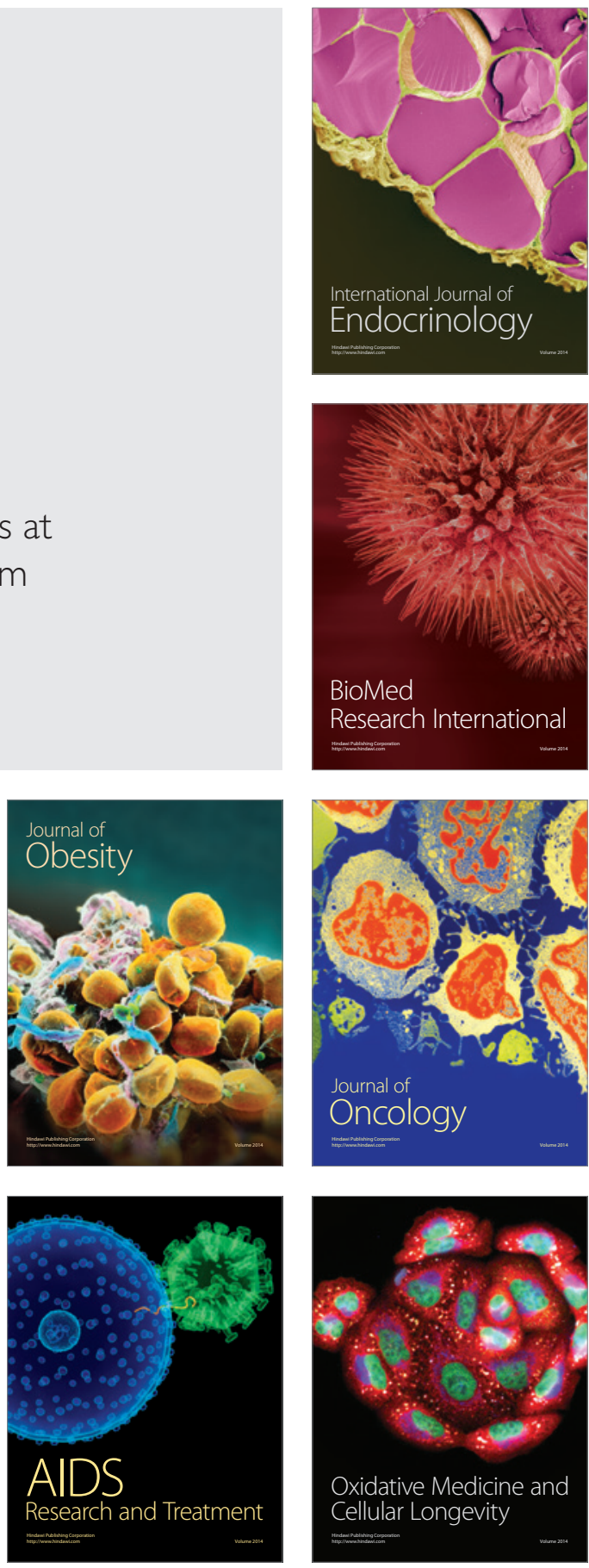